\title{
La guerra de las palabras. Análisis lexicométrico de la bibliografía de Maryse Bertrand de Muñoz sobre la guerra civil española
}

\author{
The Words War. Lexicometric Analysis of Maryse Bertrand \\ de Muñoz's Bibliography about the Spanish Civil War
}

Recibido: 27-II-2013

\author{
Michel Matly \\ Université Blaise Pascal, Clermont-Ferrand
}

Aceptado: 1-X-2013

\section{Resumen}

Este artículo presenta las conclusiones de un análisis lexicométrico de alrededor de 42.000 títulos de la bibliografía de Maryse Bertrand de Muñoz sobre la guerra civil española. El objetivo es probar la utilidad de dicho análisis, como método complementario del análisis bibliográfico convencional, para caracterizar las dimensiones y evolución de la representación de la contienda desde su inicio en 1936. El análisis lexicométrico muestra los cambios en el vocabulario relativo a la guerra; la evolución de las perspectivas histórica, política y antropológica; el peso relativo concedido en cada momento a su dimensión nacional e internacional; y, finalmente, la dinámica en la aparición y desaparición de las diferentes temáticas que tratan las obras sobre la guerra.

Palabras clave: Guerra Civil española (1936-1939), Representación, Percepción, Estadística, Lexicometría.

\begin{abstract}
This paper presents the conclusions of a lexicometrical analysis of around 42,000 titles of the bibliography of Maryse Bertrand de Muñoz about the Spanish Civil War. It pretends to demonstrate the interest of such a method, besides and in complement to conventional bibliographical analysis, in order to characterize the dimensions and evolutions of the representation of the conflict since it's beginning in 1936. The method allows identifying the changes of vocabulary related to the war, the evolutions of interest for its historical, political or anthropological approaches, the relative importance given to its national and international dimensions, the disappearing, re-discovery and emergence of associated thematic.
\end{abstract}


Keywords: Spanish Civil War (1936-1939), Representation, Perception, Statistics, Lexicography.

\section{Introducción}

La abundancia y calidad de las obras sobre la memoria de la guerra civil española muestran el interés que ha suscitado y suscita la contienda, tanto en España como en el extranjero. El análisis bibliográfico convencional de esta ingente producción ha puesto en evidencia, por un lado, que la memoria de la guerra es una memoria polisémica. Así, ha quedado establecido que ni siquiera existe una representación de la guerra socialmente compartida o, al menos, socialmente admitida, sino una constelación de memorias, de miles de memorias.

Por otro lado, la bibliografía sobre la memoria de la guerra subraya que dicha memoria no es estática, sino que evoluciona. Y ese cambio se debe, unas veces, a las necesidades inmediatas de instrumentalización política, siendo un cambio forzado, mientras que otras veces su evolución no es más que producto esperable de la propia evolución de la sociedad que la rememora.

Cualquier estudio sobre la memoria o representación de la guerra civil española debe partir de este marco de referencia, especialmente en cuanto a los dos elementos referenciales principales ya citados: la polisemia de esta memoria y su evolución. La primera parte de este trabajo está dedicado a ello.

¿Pero estas conclusiones del análisis bibliográfico tradicional podrían sustentarse mejor? ¿Podrían apoyarse con datos cuantitativos o datarse con mayor precisión? Estos son los interrogantes a los que quisimos buscar respuesta al plantear el análisis estadístico y lexicométrico de los 42.000 títulos de la impresionante bibliografía reunida por Maryse Bertrand de Muñoz ${ }^{1}$.

Se presentan aquí cuatro campos de resultados de este análisis, relativos a las siguientes cuestiones: 1) evolución y localización de la producción de obras desde el principio de la contienda; 2) aspectos de la guerra que han sido foco de atención a lo largo de los años y qué tipo de obras han generado; 3) aparición y desaparición de las palabras más usadas para hablar del conflicto; 4) centros de interés de las obras (personajes, acontecimientos, conceptos, etc.) y su evolución.

\section{Las representaciones de la Guerra Civil}

\subsection{La polisemia}

La mayoría de las obras dedicadas a explorar la memoria de la guerra civil española y su transmisión se han publicado a partir de los años 90. El Instituto

1. BERTRAND DE MUÑOz, Maryse, Bibliografía de la guerra civil española de 1936-1939, Madrid, CD Universidad Nacional de Educación a Distancia, 2007, 2.307 pp. + 103 pp. (anexos). 
Cervantes identifica cerca de 350 libros sólo entre 1997 y 2006. Entre ellos, destacan: Memoria y olvido de la Guerra Civil española (Aguilar Fernández, 1996), Memoria de la Guerra Civil: los mitos de la tribu (Reig Tapia, 2000), Guerra civil: mito y memoria (Aróstegui-Godicheau, 2006), La guerre d'Espagne en héritage (Corrado-Alary, 2007), La odisea de la memoria (Cuesta Bustillo, 2008).

Los autores subrayan que la contienda se puede abordar desde muchas perspectivas: sus orígenes y legitimidad; sus consecuencias para las épocas posteriores; su imbricación internacional y la participación de potencias y/o voluntarios extranjeros; sus dimensiones militar, política, religiosa o territorial; su consideración de "guerra romántica" (la "última" guerra de ideas, aunque después hubo más) que movilizó a intelectuales y poetas; su consideración de guerra de religión, o de conflicto cuasi colonial, de guerra entre vecinos, que dividió a familias y amistades; la violencia extrema que desató y que perduró en la posguerra... Todo ello permite proponer representaciones diversas de la tragedia de la guerra civil española; representaciones convergentes, antagónicas o complementarias, estables o cambiantes, según las convicciones de cada uno, en un espectáculo siempre renovado.

Ya sólo la manera de nombrar o denominar a la guerra y a sus participantes significa tomar partido por una visión, un campo, es elegir su memoria. Como opina Paloma Aguilar Fernández², se trata más que de una simple cuestión terminológica, pues el vocabulario refleja la manera de concebir, interpretar y aún recordar la guerra. Analizando la serie de artículos publicados en el diario El País con motivo del 50, 60 y 70 aniversario del principio de la guerra, Mónica Musci ${ }^{3}$ recuerda que el término "guerra civil" no estaba admitido en la España franquista y le sorprende que algunos intelectuales sigan usando en 1986 el término, inodoro e impropio, de "guerra de España". Puede que se hayan abandonado los términos más excesivos que sirvieron durante e inmediatamente después de la guerra, como rojo o fascista, pero Catherine d' Humières ${ }^{4}$ subraya la dificultad de nombrar a los contendientes en las lecciones escolares, sin usar nombres impropios o partidarios, aunque se tenga la mejor voluntad del mundo.

2. Aguilar fernández, Paloma, Memoria y olvido de la Guerra Civil Española, Madrid, Alianza Editorial, 1996.

3. MUSCI, Mónica, "Representaciones de la Guerra Civil en el diario El País: 1986, 1996, 2006", Olivar. Revista de literatura y cultura españolas, no 8 (2006), pp. 331-350.

4. D'HUMIĖRES, Catherine, "Comment assumer l'héritage de Caïn. Enseigner la Guerre Civile: le défi de la démocratie", en CORRADo, Danielle y alary, Viviane, La guerre d'Espagne en héritage. Entre mémoire et oubli (de 1975 à nos jours), Clermont Ferrand, Presses Universitaires Blaise Pascal, 2007, pp. 141-152. 
La multiplicidad de la representación de la guerra civil refleja la complejidad de la sociedad española que la contempla. El exilio o la represión de muchos intelectuales consiguieron que una parte importante de los creadores de opinión, del mundo político, de la prensa, de la literatura, inclusive de izquierda, sean hijos del campo franquista o hijos de aquellos que, indiferentes políticamente, se dedicaron a (sobre)vivir o a progresar socialmente en la sociedad española de la época franquista. Para una gran parte de la población española actual la guerra civil tiene definitivamente poca importancia. Incluso los herederos del campo republicano desvalorizan hoy a la base social de la República y a sus combatientes. Son pocos los que se identifican con los obreros o con los campesinos de aquella época o que intentan entender sus frustraciones y motivaciones, tan alejadas de las aspiraciones de hoy en día. Buena parte de estos herederos se unen al colectivo de los que no quieren saber, de los que consideran la contienda como "la guerra de papá" o las "batallitas del abuelo".

El silencio sobre la guerra civil es por sí mismo objeto de análisis entre los investigadores de la memoria. Paloma Aguilar Fernández ${ }^{5}$ afirma que el silencio sobre la guerra ha conllevado renuncias y frustraciones, pero también ha jugado un papel positivo en la cohesión de la sociedad postfranquista. Para Francisco Ayala ${ }^{6}$, el silencio en los años 90 sobre la guerra civil no sólo se debe a un acto de prudencia política, sino también a la pérdida de los valores políticos del conflicto.

Al mismo tiempo, el recuerdo de la guerra no remite sólo a la violencia y el sufrimiento pasados, sino también coloca en primera línea frustraciones, dolores y silencios del presente. La recopilación de informaciones y testimonios sitúa de nuevo el conflicto en el presente. Y con ello se pone en evidencia la inoportunidad de los símbolos bélicos franquistas que permanecen en calles, plazas y edificios públicos; la ofensa de miles de cuerpos de víctimas sin sepultura. No se trata ya de la guerra, ni siquiera de su memoria, sino de la sociedad española contemporánea.

La indignación y el dolor frente a la violencia y la represión durante la guerra y la posguerra, se extiende también ahora en torno al reconocimiento actual de los hechos. Indignación y dolor frente a las posiciones reacias de autoridades a la retirada de símbolos franquistas o a apoyar las exhumaciones impulsadas por el llamado "movimiento de recuperación de la memoria histórica"; frente a la indiferencia o el desprecio por los familiares de las víctimas de ejecuciones extrajudiciales y su necesidad de contar lo ocurrido, de buscar, encontrar y enterrar decentemente a los muertos que yacen clandestinamente por toda

5. aguilar fernández, Paloma, Memoria y olvido de la Guerra Civil..., p. 4.

6. AYALA, Francisco, "El sentido de una pregunta", artículo en El País, 18-VII-1996. 
la geografía española. Todos estos factores hacen que la representación de la guerra civil española no sea tan simple como esa militante y romántica visión exterior, algo mitológica, alimentada por la memoria del exilio y de las brigadas internacionales.

Son también objeto de estudio en los trabajos sobre la representación de la guerra civil, el peso específico de los diferentes aspectos de la contienda, así como los mecanismos de transmisión de esta memoria. La instrumentalización política de la memoria, su transmisión institucional o escolar, la transmisión familiar, la creación literaria o cinematográfica, la apertura de archivos o la publicación de testimonios privados, el surgimiento de movimientos de la sociedad civil, como el ya citado de exhumación de ejecutados extrajudiciales, etc. entrelazan sus efectos y moldean un universo de memorias que no deja de evolucionar.

\subsection{Evolución de la perspectiva sobre la guerra desde la Transición española}

Desde 1976 se han producido importantes y significativos cambios de perspectiva en el tratamiento de la guerra civil. Para Alberto Reig Tapia, el periodo anterior a 1986 sirvió sobre todo para colmar el déficit de información de los españoles sobre los hechos de la guerra. Josefina Cuesta defiende que en la Transición y en los años que siguieron se recupera la memoria republicana, a través de múltiples acciones: amnistía, reparación a las víctimas del franquismo (reconocimiento de funcionarios públicos al servicio de la II República para el cobro de indemnizaciones o pensiones, por ejemplo), apertura de algunas fosas comunes, regreso de exiliados, visitas y homenajes a brigadistas, reaparición tímida de guerrilleros y topos escondidos desde décadas ${ }^{7}$.

François Godicheau ${ }^{8}$ subraya que el periodo de la Transición se caracteriza por el deseo de revelar "la historia objetiva" de la guerra civil, no sólo con el propósito de de-construir el relato franquista, sino con el principal objetivo del "nunca más", de evitar que tal enfrentamiento pueda volver a producirse. En este sentido, a partir de 1980, diferentes movimientos tácticos se dirigen a limar las asperezas de la guerra y a conseguir que su relato deje de alimentar la división de la sociedad española. Se trata de borrar a sus actores atribuyendo ideas y acciones a siglas despersonalizadas y sin significado actual (POUM, CNT...), circunscribirla en una reflexión más amplia sobre la condición huma-

7. REIG TAPIA, Alberto, Memoria de la Guerra Civil: los mitos de la tribu, Madrid, Alianza Editorial, 2000.

8. GODICHEAU, François, "Lhistoire objective de la guerre civile et la mythologie de la Transition", en CORRADO, Danielle y ALARY, Viviane, La guerre d'Espagne en héritage..., pp. 69-96. 
na y considerarla como una locura o una tragedia que arrastra a la población, o finalmente y siempre que ha sido posible, silenciarla.

En la misma línea, Josefina Cuesta ${ }^{9}$ considera que el aniversario de 1986 sirvió para sustituir las perspectivas partidarias por una mirada serena de la guerra, para no herir al otro campo, para desplazar la contienda del terreno político al debate intelectual, para externalizar sus causas, considerándolas internacionales, ineludibles o inevitables para las manos españolas. Guernica, por ejemplo, donde aviones alemanes bombardearon poblaciones españolas indefensas, aparece como un símbolo ambiguo porque tiende a borrar el carácter de enfrentamiento entre españoles de la guerra civil.

Tras el aniversario de 1986, empieza a considerarse que el tema de la guerra ya se ha tratado ampliamente y que queda poco trabajo para los historiadores. Tampoco la guerra tiene ya un valor positivo, constructivo. En una entrevista del diario El País, Francisco Ayala ${ }^{10}$ afirma que ya nadie se siente solidario con las posiciones ideológicas en juego durante la contienda. El aniversario de 1996 busca en primer lugar reforzar el carácter de hecho o acontecimiento histórico, alejándola de la sociedad contemporánea ${ }^{11}$. El foco cambia: no interesa tanto la historia de la guerra, sino la memoria de la guerra. Es el momento para la salida a escena de otros especialistas: politólogos, sociólogos, semiólogos...

Josefina Cuesta señala que en los años 90 se asiste a un doble fenómeno en torno a la guerra: por un lado se propicia su silenciamiento, por el otro la recuperación de su memoria. Julio Aróstegui y François Godicheau ${ }^{12}$ colocan en los años 90 el fin de la memoria de "reconciliación", que es sustituida por una memoria de "restitución o reparación", impregnada de valores morales pero también de revanchismo de ambos lados. Tal vez se pueda añadir (y los ejemplos que ofrece Cuesta van en ese sentido) que la tendencia a silenciar la guerra se sitúa en Madrid o Barcelona, mientras el interés por la memoria se acentúa en ciudades de menor tamaño. En esa época se observa una proliferación de historias regionales y locales, de testimonios escritos y filmados sobre la contienda que denotan una doble preocupación: reunir todo lo que pueda pertenecer al patrimonio material y simbólico de la guerra ${ }^{13} \mathrm{y}$, de forma más

9. CUESTA Bustillo, Josefina, La odisea de la memoria. Historia de la memoria en España. Siglo XX, Madrid, Alianza Editorial, 2008.

10. AYALA, Francisco, "El sentido de una pregunta...", p. 5.

11. CUESTA BUSTILlo, Josefina, La odisea de la memoria..., p. 6.

12. ARÓSTEGUI, Julio y GODICHEAU, François, Guerra civil: mito y memoria, Madrid, Marcial Pons Historia, 2006.

13. BERTRAND DE MUÑOz, Maryse, "La guerre civile espagnole et la production romanesque des quinze dernières années face à celle de la Transition à la démocratie", en CORRADO, Danielle y ALARY, Viviane, La guerre d'Espagne en héritage..., pp. 31-46. 
o menos consciente, a través de esa recopilación exhaustiva, dar el tema por zanjado, es decir, terminar con la guerra civil ${ }^{14}$.

En España se puede seguir la evolución de la percepción de la guerra civil como un movimiento pendular: la guerra se aleja y se acerca, la sociedad española se solidariza con ella y se aparta, con pérdida de su valor y recuperación posterior:

- En la primera década después de la muerte de Franco (1976-1986), la guerra y la posguerra interesan, y mucho, debido a la urgencia por sustituir la historiografía oficial franquista de los 40 años anteriores.

- Más tarde viene la comprobación de que los valores en conflicto ya no se corresponden con los de la España moderna (1986-1996); es una época de retracción, o quizás de reflexión. En estos años 90 la utilidad de la guerra se pierde, sus contornos se deforman, el silencio es espontáneo, sin que la esfera política lo propicie, aunque este silencio juegue a su favor. La contienda no proporciona claves de una representación útil para la sociedad española de los 90, la mirada ha vaciado progresivamente el contenido político de la contienda y desconsiderado el compromiso de los hombres y mujeres que participaron en ella.

- Pero a partir de 1997 la guerra recupera protagonismo. Ya no se enfoca en sus causas, sino en sus consecuencias, en el impacto de sus consecuencias sobre los valores de la sociedad española contemporánea. La primera década del siglo XXI encuentra nuevos valores en la reflexión antropológica de la guerra, y esos valores impulsan la acción política con su correspondiente cuota de polémica y enfrentamiento. Existe acercamiento porque una nueva percepción de la guerra la amarra al tiempo presente, con reivindicaciones inmediatas y concretas (movimiento de apertura de fosas, retirada de símbolos, etc.).

- Paralelamente, y sin estar asociada a ninguna época concreta o asociada a todas, una voluntad institucional de silencio, que no ceja desde 1975 hasta ahora.

En el extranjero, la evolución de la representación de la guerra civil española, sin ser exactamente igual, comparte muchos elementos de la evolución dentro del país. La mirada sobre la contienda española sigue la evolución de la mirada occidental sobre la política, la guerra en general y, finalmente, sobre la propia sociedad.

14. GODICHEAU, François, "L'histoire objective de la guerre civile et la mythologie de la Transition...", p. 6. 
Así, según Denis Rodrigues ${ }^{15}$, los libros de texto franceses de enseñanza Secundaria del español han pasado de un enfoque partidario a la descripción antropológica. Desde los años 60 a mediados de los 80 , los libros de texto dedican escasa atención a los hechos de guerra y mucho a su significado político. Es una representación (republicana) del combate entre dos ideales: uno violento, católico, antiparlamentarista, antirregionalista, hostil a las influencias liberales extranjeras; el otro, prendado de justicia, verdad y libertad, defensor de la causa de los humildes.

Le seguiría un segundo periodo, entre 1987 y 2002, que el autor califica de "amnesia programada". En un contexto de empobrecimiento general de los contenidos, los libros de texto de español dan menos importancia a la guerra civil, no la consideran ya como un momento importante de la historia española. La representación es más neutral, más distante, sobre un combate entre ideologías ya caducas (fascismo, comunismo). Finalmente, la primera década del siglo XXI marca el regreso de los libros de texto a un enfoque más analítico, a una reflexión más antropológica que política, como reflejan los títulos usados en los apartados ("Vivir juntos", "Juegos de poder", "Relación con el mundo"), acercando de nuevo la guerra civil española al introducirla en la reflexión sobre la sociedad contemporánea.

\section{El análisis lexicométrico}

\subsection{El método}

Se ha llevado a cabo un análisis lexicométrico con el objetivo de conocer su utilidad para confirmar, completar, cuantificar de alguna manera y datar mejor las conclusiones de los análisis bibliográficos sobre la memoria de la guerra civil.

Este análisis se ha realizado sobre los títulos recogidos en las 2.400 páginas de la impresionante obra de Maryse Bertrand de Muñoz. En ella, la bibliógrafa recoge 42.000 referencias fechadas relacionadas con la guerra civil española, entre 1936 y 2007: publicaciones diversas (documentos, ensayos, memorias, novelas y cuentos, biografías y autobiografías, poesía, teatro, tebeos y cómics, hasta libros de cocina, ...), películas, canciones, etc. producidos desde el principio de la contienda.

El análisis realizado ha consistido en determinar la distribución de frecuencias del tipo de obra, del tema tratado, del lugar de publicación (dentro o fuera del país; según la ciudad o región española) y de palabras (eventos, asun-

15. RODRIGUES, Denis, "La guerre d'Espagne dans les manuels d'espagnol: de l'approche partisane à la description anthropologique", en CORRADO, Danielle y ALARY, Viviane, La guerre d'Espagne en héritage..., pp. 143-167. 
tos, lugares, personas que han suscitado interés) a lo largo de los 71 años que cubre esta recopilación. Interesa especialmente la evolución ya que el objetivo era caracterizar los cambios de perspectiva y representaciones de la guerra civil española a lo largo del tiempo.

Se transfirió la versión digital de la obra de Bertrand de Muñoz a hojas de cálculo, para poder realizar las siguientes operaciones:

- Extracción de las referencias datadas (casi todas, a pocas les faltaba fecha), para permitir un desglose diacrónico, año tras año, de todo el conjunto y de los subconjuntos obtenidos con los criterios ya explicados (lugar de publicación, tema, tipo de obra...).

- Elaboración de tablas de frecuencias (y sus gráficas) según año de producción del total de las obras o de los subconjuntos obtenidos según la clasificación que la propia autora realiza: temática (militar, histórico, político, temas específicos, etc.) y tipo de obra (novela, testimonio, etc.).

- Para una parte importante del conjunto se ha podido identificar el lugar de publicación (país o ciudad extranjera; región o ciudad española) y realizar el análisis de frecuencias en el tiempo según el origen de la producción.

- Para terminar se ha realizado un análisis de frecuencias de palabras para identificar los términos más utilizados, seleccionar palabras clave y observar la evolución de su uso a lo largo de los años. Este análisis se aplicó a los títulos y no, obviamente, al contenido de cada obra.

El análisis cuantitativo puede ser legítimamente criticado: un año puede ser de escasa producción pero decisivo en la progresión de conceptos debido a la publicación de una obra magistral, mientras otro año, supuestamente fértil en cifras, puede haber publicado numerosas obras mediocres. Sin duda el método no puede sustituir al análisis bibliográfico clásico, sino proporcionar un enfoque adicional y complementario.

Por otro lado, habría sido imperdonable no aprovechar la magna obra recopilatoria de Bertrand de Muñoz y su digitalización para realizar un análisis estadístico e intentar cuantificar y datar con mayor precisión las conclusiones de los expertos en análisis bibliográfico, buscando a la vez nuevas pistas para futuros trabajos de investigación.

2.2. Las cifras de la producción creativa sobre la guerra: una estructura en catedral

De las aproximadamente 42.000 obras identificadas por Bertrand de Muñoz, alrededor de 19.000 se han producido durante la guerra, 11.000 entre 1940 y 1975 (periodo de dictadura franquista) y 12.000 entre 1976 y 2006. Estos tota- 
les incluyen la producción en España y en el extranjero, en este último caso tanto por la diáspora republicana como por autores de diversas nacionalidades.

La guerra es un tema ampliamente evocado bajo el régimen franquista: del orden de 2.000 obras al año en los años 50; 300 en los años 60. Los últimos años de dictadura y la muerte del dictador provocan una revitalización de la producción de obras sobre la contienda.

La evolución de los títulos en los siguientes 30 años presenta una estructura "en catedral" (Figura 1), con un primer pico compacto que se inicia en 1974 y alcanza su máximo en 1977, con casi 700 obras, y un segundo máximo de casi 1.000 obras coincidente con el quincuagésimo aniversario del inicio de la guerra (1986). Fuera de estos picos, el interés sigue siendo importante, con una producción anual del orden de 400 obras en la primera mitad de los años 80 y de 300 obras al año durante la década de los 90. A comienzos de la primera década del siglo XXI, la producción bajará a 100 obras al año.

Muchos autores han subrayado la importancia que ha tenido y sigue teniendo la guerra civil para los autores creativos y para el público en general. Este hecho es innegable, pero conviene matizarlo. Así, la comparación entre el total de publicaciones españolas procedentes de los anuarios estadísticos nacionales y de las obras publicadas en España sobre la guerra, tales como las identificadas por Bertrand de Muñoz, pone en evidencia que la producción de obras

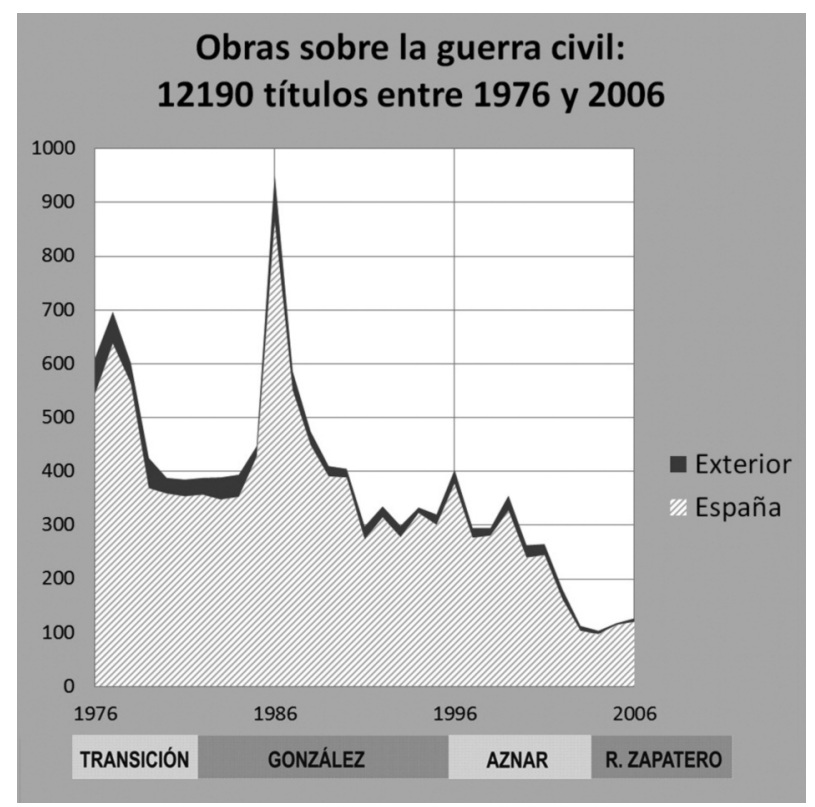

Figura 1: Número de obras por año 
dedicadas a la contienda va decreciendo de una forma más o menos lineal. Justo después de la guerra, se dedica a este tema una obra de cada tres, mientras en los años 80 pasa a ser una obra de cada diez y, después del año 2000, una obra de cada cincuenta.

La parte de producción en el extranjero (algo menos de 8.000 obras) es importante durante el período franquista: más del 30\% de las obras entre 1950 y 1970, cayendo a menos del 10\% después de 1975. Si se considera sólo el período a partir de este último año, Francia es el país que más obras produce, con un cuarto de la producción extranjera total y casi el $40 \%$ de las novelas. Le sigue Italia, más centrada en obras de memoria, como testimonios o biografías (un 18\% de las obras de memoria y un 11\% de las novelas), Estados Unidos con más ficción (un 27\% de las novelas y un 8\% de las obras de memoria) y México, que equilibra su producción en un 15\% tanto en obras de ficción como de memoria. Con resultados más discretos se encuentran países como Reino Unido, Rusia o Alemania, mientras Argentina, relativamente presente en la posguerra, ha cesado prácticamente su producción desde 1975.

\subsection{La evolución del tipo y de la temática de las obras: el cambio en la} representación de la guerra

El análisis por tipo de obra y por temática revelan el cambio en la representación de la guerra civil. Se puede observar la progresiva pérdida del sentido político de la guerra, la permanencia de algunos temas, como la violencia o el papel de la Iglesia, que no parecen haber perdido actualidad y casi terminan dominando el debate. Se puede distinguir también la diferencia de percepción de la contienda dentro y fuera de España; en el extranjero se mantiene el interés por el contenido político hasta época reciente.

El tratamiento estadístico muestra tres periodos distintos en cuanto a la representación de la guerra, estableciéndose para cada periodo un modelo estable:

- En los años inmediatamente posteriores a la guerra se articula una trilogía "política-testimonios-creación literaria" como modelo que va a perdurar hasta finales de los años 60.

- El segundo modelo de representación de la guerra se establece en la primera mitad de los años 70, antes de la muerte de Franco, con una trilogía "historia-testimonios-creación no literaria", también destinada a durar unos 30 años.

- El tercer y último cambio ocurre a comienzos del actual siglo, con características más difíciles de identificar, visto el corto periodo disponible y 
el menor número de obras. Algunos indicios permiten, más adelante, precisar el nuevo modelo en formación.

El cambio más significativo entre el primer y el segundo modelo es la pérdida de significación del sentido político de la guerra. Esta pérdida ya es perceptible durante los años del régimen franquista y sigue hasta final del siglo. Así, en España, las obras dedicadas a aspectos políticos de la guerra pasa, entre 1936 y 2006 , del 30\% al 15\%. El descenso es regular en cuanto a las obras producidas en la península, sin perturbación notable al final de la dictadura o después. El interés por las cuestiones políticas es siempre mayor en el extranjero; a finales de los años 60 se produce un verdadero divorcio entre la visión exterior e interior, haciéndose máxima inmediatamente antes de la muerte de Franco, para decaer después (Figura 2). Un divorcio que encuentra su perfecta ilustración en la película La guerra ha terminado (1969), de Alain Resnais.

Algunos elementos se mantienen a lo largo de los años y trascienden a los modelos de representación de la guerra, como la distribución de los ámbitos del análisis político que, independientemente de la época, se mantienen en un $40 \%$ de política interior, un 30\% sobre intervención extranjera y un 30\% sobre geopolítica internacional. Un cóctel sostenido que, de alguna manera, marca la visión de la guerra civil española.

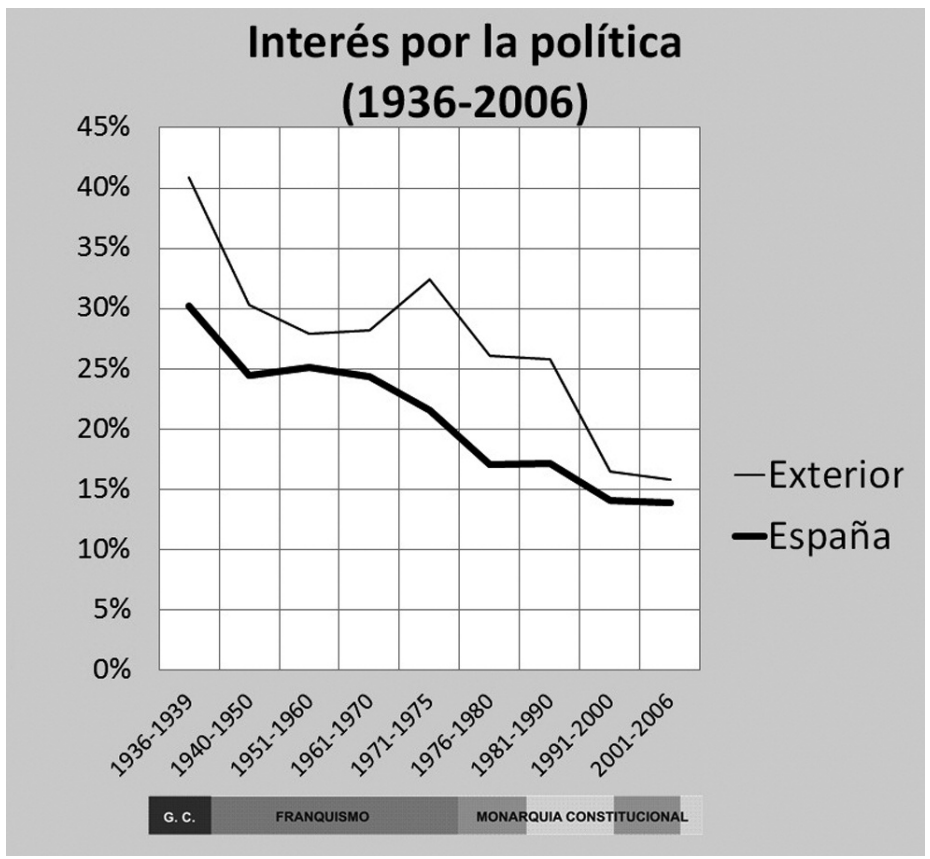

Figura 2: Porcentaje de obras dedicadas a aspectos políticos de la guerra civil 
También existe una gran constancia en la producción de obras testimoniales desde el final de la guerra, lo que confirma el buen funcionamiento del relevo generacional de los testigos de la contienda a sus descendientes.

El interés por los aspectos históricos de la contienda es algo más fluctuante (repliegue en los 80 con reactivación posterior), aunque permanece como elemento importante del período 1970-1990. Mientras, la ficción literaria, cuya importancia relativa alcanza su máximo en la década de los 60 , va perdiendo protagonismo.

A partir del año 2000 se pueden apreciar algunas tendencias: una importante reactivación de las obras testimoniales, el descenso del interés histórico y el retorno de la creación literaria.

Bertrand de Muñoz reúne aparte obras que tratan de aspectos específicos o particulares de la guerra. Su distribución también sigue modelos:

- Hasta los años 60 se articula en torno a una trilogía "legitimidad-violencia-religión".

- Al principio de los 70 el esquema cambia: la legitimidad pierde importancia, violencia y religión siguen presentes, y emergen temas como el económico y el social, en un intento fugaz de regresar sobre las causas de la guerra.

- Las décadas siguientes van a diluir las diferencias entre los modelos anteriores, regresando a un modelo comparable al de los años franquistas, esta vez centrado en violencia y religión. Efectivamente, el tema religioso permanece, siendo importante tanto para el campo franquista (persecución) como para el republicano (connivencia con la sublevación). En cuanto a la violencia, resulta una temática frecuente en las primeras fases de consolidación del régimen franquista (hasta finales de los 50), en desuso más tarde y cada vez más mencionada por la sociedad postfranquista hasta convertirse en uno de los temas principales en los primeros años del nuevo siglo.

En el caso de la producción en el extranjero, la representación de la guerra sigue la siguiente dinámica: durante el periodo franquista el modelo es similar al del interior del país, aunque algo más político y literario, produciéndose una neta divergencia a partir de 1970 debido a la ya comentada persistencia de un fuerte interés por los aspectos políticos. Los años 90 marcan cierta coincidencia entre la visión extranjera y la española interior.

En la producción extranjera coincidente con la dictadura de Franco, la religión está fuertemente presente debido sobre todo a documentos de la propia Iglesia, y hay un interés mínimo por el tema de la violencia. La reducida pro- 
ducción extranjera tras la muerte de Franco se centra en temas como la economía o el papel de las mujeres en la guerra.

\subsection{La distribución territorial en España de la producción de obras: la "ola"}

En el mundo de la edición española del siglo XX existe una constante: la paridad entre Madrid y Barcelona, dos gigantes que han editado año tras año prácticamente el mismo número de títulos. El equilibrio casi ha sido perfecto en los últimos 70 años, aunque Madrid se adelante ligeramente en los años 80 y Barcelona parezca más afectada por la crisis del sector desde 2004. Simultáneamente las dos ciudades han perdido peso debido a la descentralización de la edición: Madrid y Barcelona editaban en 1960 alrededor del 80\% de los títulos, mientras que a principios de los años 2000 suman ya solo el 60\% de la edición española.

Las obras relacionadas con la guerra civil editadas en Madrid y Barcelona representan dos tercios del total, unas 10.000 obras. Madrid produce más obras durante la contienda y, sobre todo, bajo el régimen franquista, que prefiere la palabra "madrileña" al menos hasta la década de los 60. La muerte de Franco facilita un surgimiento de la palabra "catalana": durante diez años la producción de Barcelona sobre la guerra va a ser superiora la de Madrid, llegando casi a doblarla en algunos momentos. La producción vuelve a equilibrarse a partir de 1985, con un "efecto conmemoración" más marcado en Madrid (1986, 1996) y cifras más elevadas de Barcelona fuera de estos aniversarios.

El análisis lexicométrico permite observar que, al final del franquismo, la producción de obras sobre la guerra atraviesa España como una ola (Figura 3), con un recorrido principal de nordeste a suroeste. Las regiones más cercanas al campo republicano parecen ser las primeras en alzar su palabra de manera fuerte, aunque la geografía prevalece sobre la historia y el antiguo color político se torna secundario. Así, en la década de los 70 nace la ola, rápida y potente, en Cataluña, Aragón, País Vasco, Cantabria y Asturias. En los 80 alcanza Castilla y León, Madrid, Valencia y Murcia, rozando Galicia en La Coruña y Andalucía por Granada. Finalmente llega al resto de Andalucía y Galicia, y a Extremadura, Baleares y Navarra, la olvidada del norte. Sólo algunos bastiones de la España más tradicional, como Santiago de Compostela o Toledo, parecen poco afectados.

La comparación con una ola intenta representar la dinámica de distribución territorial de la producción de obras, del interés por la guerra: el crecimiento hasta un máximo a partir del cual decrece en cada territorio, región o ciudad. Así, Sevilla ve crecer su interés por la guerra cuando Barcelona empieza a apartar la vista, en un momento en que las metrópolis españolas ceden la palabra 

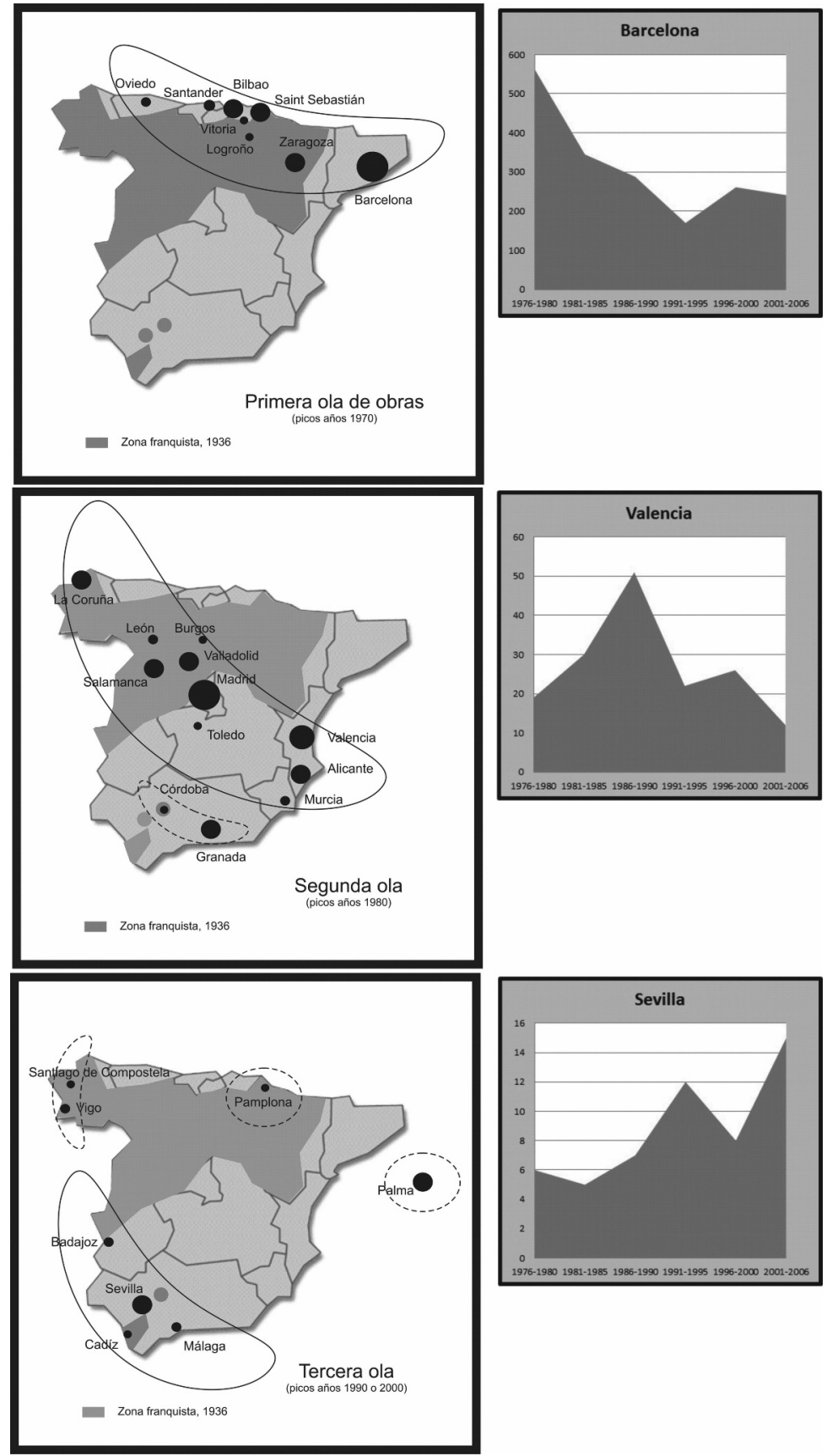

Figura 3: Localización de los picos de publicación y ciudades representativas por décadas 
a ciudades medianas, como si la evocación de la contienda funcionara como una catarsis a la que han de someterse cada una de las regiones y ciudades. El recorrido de esta ola en parte se debe a la publicación de investigaciones de proximidad e información local y regional. La información de la guerra se concreta para cada territorio, y su difusión seguramente ha contribuido a la construcción de las nuevas representaciones de la guerra que surgen con el cambio de siglo.

\subsection{Nombrar la guerra}

El análisis semántico proporciona algunas claves de la evolución de la representación de la contienda: una guerra civil que ha perdido y reencontrado su nombre, mientras pocos de sus protagonistas se hubieran reconocido en las apelaciones actuales de los dos campos: franquista y republicano. El abandono de palabras, la recuperación de términos en desuso o la popularización de nuevos términos atestigua los cambios de perspectiva a lo largo del tiempo.

La guerra civil española es también una guerra de palabras, como lo demuestra que la palabra propaganda sea la más utilizada después del término guerra y muy por delante de las demás. Pero siendo una palabra tan abundante durante la contienda, encuentra una muerte rápida. No es la única: por ejemplo, partido o miliciano ya pertenecen al pasado. Otras nacen o renacen, como represión o violencia en las décadas de los 80 y 90. Palabras antiguas reaparecen tardíamente, pero desnudas de su carga inicial, como cruzada o rojo. Incluso puede considerarse que algunas palabras no han nacido todavía: retirada no aparece nunca (surgirá después de 2007) y campo de concentración casi nunca en los 42.000 títulos.

El nombre de la guerra es un asunto complejo (Figura 4). Durante la contienda se utiliza guerra civil en los tres cuartos de los casos, o más sencillamente, la guerra. En el bando vencedor, el uso de cruzada conoce su época dorada en los años 50 y su declive es brevemente compensado por el de guerra de liberación en los años 60. En el otro extremo del arco/espectro político, la revolución española se populariza hasta los años 50 y decrece luego, a pesar de un fugaz regreso a la muerte de Franco.

El uso de guerra civil es minoritario después de la contienda, ausente en el interior y reservado a la diáspora republicana. Al final del régimen franquista, guerra civil se va a imponer y aparece en el $60 \%$ de las referencias del conflicto entre 1980 y 2000. El término más corriente en los años franquistas es el desnudo guerra, contaminado en los años 60 y sobre todo 70 por el de guerra de España, apelación algo extraña en el contexto español y ahora algo abandonada ${ }^{16}$.

16. El término "Guerra de España" no ha desaparecido totalmente; se puede encontrar, por ejemplo, en un artículo de perspectiva claramente pro-franquista: "Los oficiales moros", 


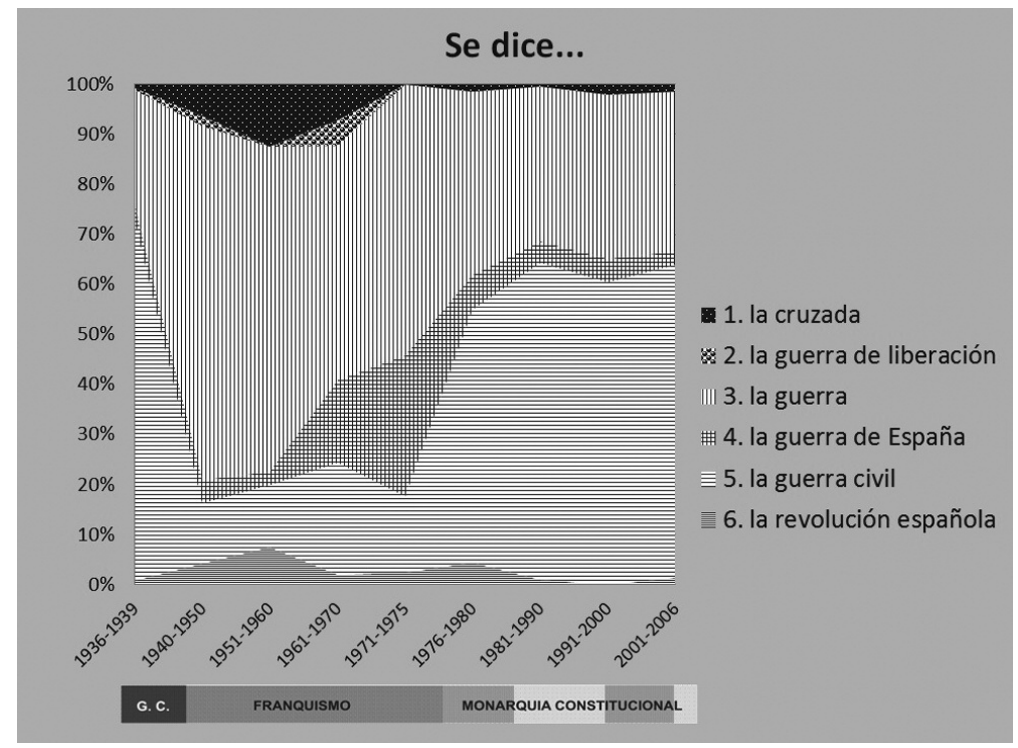

Figura 4: Porcentaje relativo de los nombres atribuidos a la guerra

¿De qué bando se habla más? Las obras de la posguerra española hablan esencialmente de los vencedores, mientras las obras posteriores a la muerte de Franco, esencialmente de los republicanos, al menos hasta los años 90 cuando la tendencia se va invirtiendo y se vuelve a introducir el bando opuesto. En las publicaciones en el extranjero, las referencias al campo republicano dominan indudablemente, pero también en los últimos años existen más referencias al campo franquista.

Todo esto marca nítidamente períodos en la representación de la guerra:

- Los franquistas han hablado de sí mismos desde la guerra. El bando republicano hace lo mismo desde que vuelve a ser posible, a partir de 1976. A partir de esa fecha existe una urgente necesidad de dar a los republicanos un protagonismo que se les ha negado. No se trata de dar una visión republicana de la guerra, en oposición a la franquista, sino una visión de los republicanos en la guerra. El adversario, la confrontación, no están incluidos y eso, en definitiva, es del agrado de los herederos de ambos bandos.

- A partir de los años 90, y sobre todo con el comienzo del nuevo siglo, se convoca a los franquistas, éstos vuelven a escena, a entrar en la temática

del coronel Juan Ignacio Salafranca, publicado en 2013 en la Revista de Historia Militar del Instituto de Historia y Cultura Militar del Ministerio de Defensa, con ocasión del centenario del protectorado de Marruecos. 


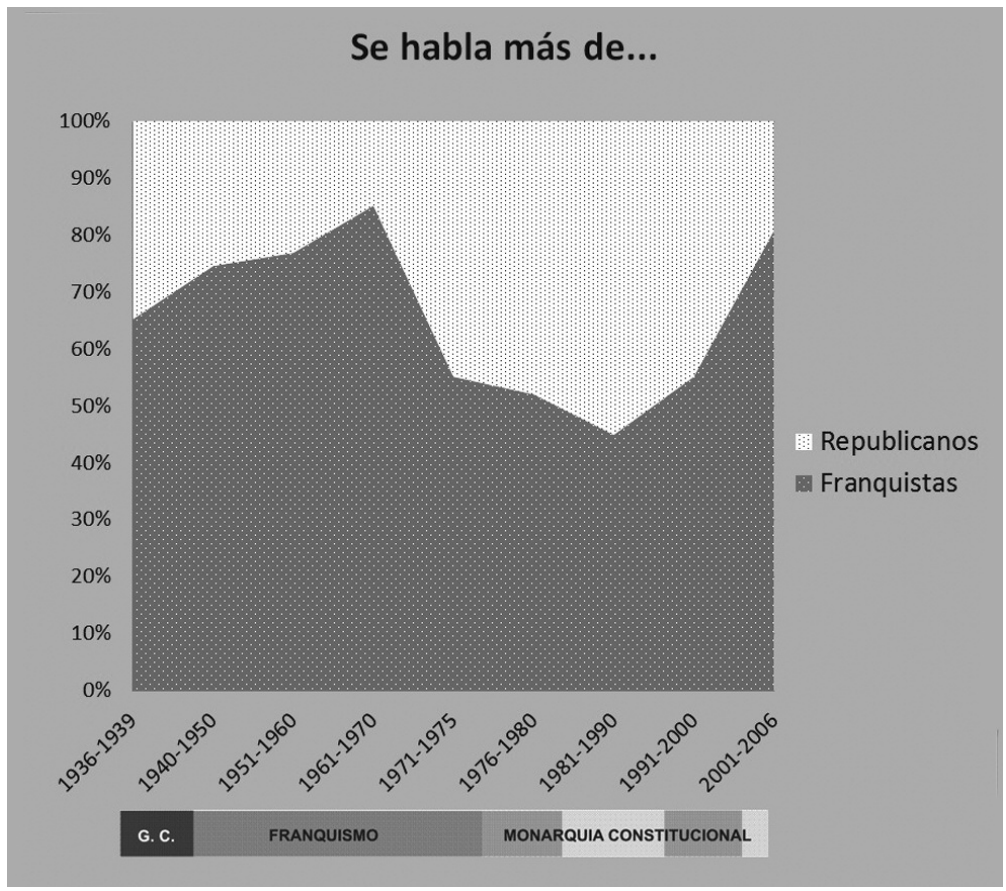

Figura 5: Porcentaje relativo de obras dedicadas a uno $\mathrm{u}$ otro grupo

de las obras. Con ello, el recuerdo de la guerra se hace más espinoso. Se puede concluir que el movimiento de recuperación de la memoria histórica es el ejemplo palpable de la reintroducción del franquista en la memoria republicana (Figura 5).

Ni franquistas ni republicanos han participado en la guerra civil española, si nos atenemos a cómo se llama mayoritariamente a los contendientes en las obras contemporáneas a la guerra. Por un lado, uno es nacional o fascista según quién le nombre (sublevado tiene una frecuencia insignificante). Por otro, uno es rojo para el adversario o miembro de algún partido o movimiento: anarquista, socialista, comunista, etc.

Después de la guerra, los nombres de los participantes han sufrido el paso del tiempo con diferente fortuna. Así, nacional, un indudable éxito de marketing que se mantiene durante el franquismo prácticamente se abandona tras la muerte de Franco, aunque regresa durante un corto espacio de tiempo. Mientras, franquista ha sustituido definitivamente a fascista, pero sin llegar a eliminarlo del todo. El término republicano no consigue imponerse hasta los años 80 , borrando al despreciativo rojo que, en general como provocación, resurge fugazmente en los años 2000. 
El nombre de partidos y movimientos siguen dinámicas propias. Así, carlista casi no aparece, mientras Falange conoce varios periodos: su frecuencia cae durante el franquismo, que prefiere el término Movimiento, pero resurge en 1970, se usa mínimamente tras la muerte de Franco y en los 80, para volver a aparecerr en los 90 y sobre todo a partir del 2000. Esos periodos representan respectivamente: el control de los partidarios de Franco, las reivindicaciones de la extrema derecha durante la agonía del régimen y, finalmente, la ausencia y el regreso posterior del "otro" en la memoria republicana.

Otra palabra, Iglesia, moderadamente citada hasta los 50 , va a tener un peso creciente hasta la década de los 80 , retrocediendo en los 90 y volviendo después del cambio de siglo.

La palabra más usada hasta el final de los años 50 es comunista: el enemigo por excelencia de los franquistas y su pasaporte para ser aceptados en la guerra fría. Este término, ausente entre 1960 y 1975, vuelve a la actualidad brevemente tras la muerte de Franco y será escasamente utilizado a partir de entonces. Sus traducciones (communiste, communist) son también las menciones ideológicas más frecuentes en las primeras obras producidas en el extranjero, con un descenso temporal en los años 60 y una desaparición casi total tras la caída del muro de Berlín.

Anarquista, poco usado durante el conflicto, ignorado hasta la década de los 60, disfruta de un interés particular en las obras españolas de los 70, mientras sus traducciones son más frecuentes en los 60 y en los 80 .

Finalmente, en las obras españolas, socialista mantiene un nivel modesto desde la contienda hasta los años 50, aumenta significativamente en los 80 (las legislaturas del presidente González) para bajar después. Paralelamente no se usa nunca o casi nunca en las obras extranjeras. El papel del primer partido de España en las elecciones de 1931 y 1936, ninguneado por otras corrientes ideológicas más extremas, parece no considerarse determinante en el desarrollo de la contienda.

Las palabras república y revolución son las palabras más asociadas a la guerra civil. El término revolución se impone en la era franquista, como la justificación de los vencedores para su levantamiento, pero también como objetivo para parte de los vencidos. Su importancia disminuye hasta los años 70 , momento en el que vuelve a tomar vigor; casi desaparece en las décadas de los 80 y 90 para finalmente reaparecer, aunque de forma limitada, en los años 2000. El término república desaparece con la posguerra, vuelve con un primer máximo en la primera mitad de los años 70, antes de la muerte de Franco y de la aceptación de la monarquía por la izquierda española, retrocede luego para volver a cobrar importancia en los 90 y, sobre todo, en los 2000. El término repú- 
blica, utilizado solo o en oposición al levantamiento o al franquismo, tiende de hecho a asimilarse a la izquierda. Y eso a pesar de que, como ocurrió en 1934 y 1935 (y evidentemente en muchos otros países fuera de España) la república pueda ser de derechas; pero no es de esta república de la que hablan las obras que nos atañen.

Memoria, represión y violencia son palabras especialmente importantes en la última década del periodo de la bibliografía. El término memoria, que nunca desapareció durante la posguerra pero se mantuvo a un nivel modesto, conoce un resurgimiento justo antes de la muerte de Franco, para replegarse hasta los años 80, adquiriendo una importancia sin precedentes en los años 90 y 2000. Por otra parte, represión y violencia, palabras casi desparecidas del vocabulario de la guerra después de 1950, reaparecen tímidamente en los años 80, más claramente en los 90 (al menos, represión) y cobran una importancia considerable con el comienzo del nuevo siglo. Este florecimiento es coherente con la reintroducción del franquista en la memoria de la guerra asociado sobre todo a los movimientos de recuperación de la memoria histórica que luchan por la localización y excavación de los enterramientos de ejecutados extrajudiciales y por la revelación de la verdad sobre la adopción forzada de niños.

Muy importantes durante el conflicto son las palabras de la autonomía catalana (Catalunya, Generalitat), que regresan con una alta frecuencia en los años 80 y 90, y algo menos en los 2000. Como señala Paloma Aguilar, la sociedad española evoca la guerra no tanto en sus efemérides, sino en momentos de decisiones políticas capitales, como pueden ser la aprobación de los estatutos de las comunidades autónomas ${ }^{17}$.

Finalmente, la mención a otros países muestra que la implicación extranjera en la guerra sólo es un tema importante hasta la década de los 80. Los nombres de Francia e Italia son los más mencionados, prácticamente los únicos en las últimas décadas, desapareciendo el interés por la participación de Alemania y Rusia. La razón puede ser un cambio de perspectiva: se pasa de la reflexión geopolítica de alto nivel a una visión más testimonial de la participación extranjera en la contienda. Sin duda los protagonistas y testigos directos de la guerra se codearon más con soldados italianos y gendarmes franceses que con los aviadores alemanes o los técnicos rusos.

\subsection{Soldados contra poetas}

Parece que la guerra civil fue un conflicto de pocas batallas, si nos atenemos a su evocación en el conjunto de las obras. Prácticamente sólo están presentes

17. aguilar fernández, Paloma, Memoria y olvido de la Guerra Civil..., p. 4. 
las batallas del Ebro, muy modestamente, y Guadalajara, victoria de los españoles (republicanos) sobre los italianos (y como tal algo celebrado por los dos bandos). Resisten algunos nombres relacionados con hechos heroicos o criminales de una parte u otra, como la defensa del Alcázar de Toledo o el bombardeo de Guernica, que se erigieron como símbolos pero han perdido con el tiempo buena parte de su poder de evocación. Badajoz y Paracuellos, citados a veces como encarnación de la violencia contra civiles de una parte y otra, no aparecen. En resumen, parece quedar muy poco del aspecto militar de la guerra, con batallas perdidas o mal ganadas por ambos lados y símbolos desgastados por exceso de uso en la propaganda respectiva.

Al considerar las personalidades reflejadas en los títulos de las obras, la guerra se parece a su propio tópico de contienda entre soldados y poetas o, para ser más precisos, entre Franco y Lorca. De un bando hay soldados o, mejor dicho, uno sólo, ya que la figura de Franco domina sobre todas las demás, con más o menos fuerza. Del otro bando hay poetas o, mejor dicho, hay uno sólo, ya que la figura de Lorca es omnipresente, al menos hasta los años 90 . El foco sobre Franco no es uniforme a lo largo de los años. La figura del dictador pierde mucho protagonismo en 1970, cuando el régimen parece acercarse a su fin, pero lo recobra en 1975, en tiempos de incertidumbre política, para casi ignorarlo en los años 80 , cuando existe una voluntad de dar la espalda al pasado. Pero la mirada vuelve hacia Franco a partir de los 90 y sobre todo después del año 2000, seguramente asociada a la voluntad de saldar cuentas a través del movimiento de recuperación de la memoria histórica. Además de a Franco, se menciona a José Antonio Primo de Rivera y al general Emilio Mola, aunque de forma modesta

Del lado republicano, habrá que esperar al comienzo del nuevo siglo para que aparezcan los nombres de Manuel Azaña y, con menor frecuencia, Juan Negrín. ¿Interés renovado por la política de la república o intento de asegurar raíces de izquierda para nuevas oposiciones a la monarquía parlamentaria? En cuanto a las otras personalidades citadas del bando republicano, el más citado es Buenaventura Durruti, que mantiene intacto su atractivo de héroe popular, mientras Dolores Ibárruri y Antonio Machado caen progresivamente en el olvido. A partir de los años 90 Federico García Lorca pierde su liderazgo: el tiempo de los poetas y de la "guerra romántica" ha terminado.

\section{Conclusión}

El tratamiento estadístico y lexicográfico de los títulos de la bibliografía de Maryse Bertrand de Muñoz aporta información con diverso grado de interés. Por un lado, se obtienen resultados ya conocidos u obtenidos anteriormente 
por otros especialistas, como los nombres asignados a la guerra o el retorno del franquista a la memoria republicana, y que confirman la validez del método. Por otro lado, proporciona resultados inéditos que abren nuevos campos de reflexión, como el itinerario de los lugares de publicación (la "ola") o el relativo olvido del papel de Alemania y Rusia frente a Italia y Francia.

Cada uno de estos resultados merecería indudablemente un análisis más detallado que no sería pertinente en el marco del presente artículo. Por ello, nos concentraremos únicamente sobre dos aspectos de relevancia mayor: el ritmo del cambio de las representaciones de la contienda y la situación de la imagen en estas representaciones.

La teoría de la representación social constituye sin duda un aporte inestimable de las ciencias humanas y sociales para la comprensión de una determinada sociedad en un momento dado. Su mayor debilidad es probablemente su carácter estático, su dificultad para aprehender la evolución de esa representación, su cambio. Este fue uno de los puntos principales de la famosa polémica a finales del siglo XIX entre Émile Durkheim, padre de la representación colectiva e inspirador de la teoría de la representación social, y su mentor Gabriel Tarde. El segundo reprochaba al primero su incapacidad para explicar los episodios de cambios políticos o religiosos y en particular las rupturas, las "discontinuidades enigmáticas" de la historia, parafraseando a Michel Foucault. Esa es también unas de las razones del desarrollo reciente de nuevas tesis sociológicas inspiradas en Tarde, como la Actor-Network-Theory (ANT), desarrollada a finales del siglo XX por investigadores como Bruno Latour o John Law.

Los principales teóricos de la representación social (Serge Moscovici, Denise Jodelet, Jean Claude Abric) también encuentran dificultades para tratar el tema de la estabilidad o la evolución de las representaciones y pocos de sus seguidores se arriesgan a especular sobre los mecanismos de cambio. Es significativo que los únicos ejemplos de ritmo de cambio de representación social que se pueden comparar con los resultados del presente trabajo estén o bien alejados en el tiempo (Ibn Jaldún, siglo XIV) o en el espacio (Irene Andriamifidisoa, años 1980, Madagascar). Ibn Jaldún considera que un cambio de representación social tarda tres generaciones ${ }^{18}$, mientras Andriamifidisoa estima un mínimo de 10 años para que este cambio se produzca ${ }^{19}$.

El análisis lexicográfico presentado aquí sugiere que durante el periodo considerado desde la guerra civil se conformaron tres representaciones distintas

18. Cit. por ABRIC, Jean-Claude, Pratiques sociales et représentations, Paris, PUF, 2001.

19. ANDRIAMIFIDISOA-DANICHERT, Irène, La transformation d'une représentation sociale: exemple des relations sociales à Madagascar, tesis doctoral, 1982 (cit. por ABRIC, Pratiques sociales...). 
de la contienda, con un ritmo de cambio del orden de 30 años o sea de una generación, una conclusión que tiene el mérito de ser aquí razonablemente establecida y demostrada (ver apartado 2.3). Se pueden puntualizar condiciones específicas de unas u otras décadas que podrían explicar tal o cual cambio, pero el factor biológico, el simple hecho que una generación suceda a otra, parece determinante.

Esto probablemente recuerde otro aspecto de la polémica entre Durkheim y Tarde, a saber, si lo social es un factor o una función del hombre. Durkheim (y los teóricos de la representación social) conciben lo social como un campo particular, explicativo, mientras Tarde (y los teóricos de la ANT) no lo ven como un campo autónomo, sino como un principio de conexión. Así Peter Berger y Thomas Lickman afirman que no hay estabilidad, sino trabajo permanente de legitimación y de conservación, afirmando la existencia, definiendo límites, asignando pertenencias y asegurando la continuidad ${ }^{20}$.

Un concepto es estable solamente porque una multiplicidad de actores lo mantiene gracias a comportamientos, palabras o escritos. Así, una asociación, un partido político o una iglesia existen solamente porque múltiples actores hacen que exista y no sólo los integrantes de dicho grupo sino también los que hablan o escriben sobre él. Dentro de este trabajo de mantenimiento, la renovación generacional aparece como un factor lógico de discontinuidad en la medida en que el proceso de socialización (primaria y secundaria) de los nuevos actores empieza donde termina la generación anterior.

Heredera de Gabriel Tarde, la ANT proporciona herramientas para abordar los mecanismos de cambio de las representaciones, considerando que los procesos de formación y de desagregación son los únicos realmente reveladores, contrariamente a las conexiones estables, por esencia mudas e invisibles. Parece así oportuno concentrarse en los periodos de cambio (décadas 1960-1970 y 1990-2000) si se desea profundizar en algunas de las hipótesis aquí formuladas sobre la evolución de la representación de la guerra civil.

Para terminar, se mencionará otro resultado del análisis de la bibliografía de Maryse Bertrand, que nos lleva a interrogarnos sobre la forma y finalmente sobre el contenido de las representaciones. El análisis estadístico muestra que la muerte de Franco marca una discontinuidad en la representación iconográfica de la contienda. La imagen representa un 20\% de las obras, porcentaje relativamente estable entre 1940 y 1975 . A partir de 1976 pasa a un $40 \%$ y se mantiene más o menos constante desde esta fecha. Se trata de un fenómeno

20. Berger, Peter y luckmann, Thomas, Social Construction of Reality: A Treatise in the Sociology of Knowledge, New York, Garden City, Anchor Books, 1966. 
de salto y no de una evolución continua que podría explicarse por la pérdida progresiva de protagonismo del libro frente a otros medios de comunicación.

La explicación habría que buscarla quizás, en el poder de la imagen y su relación con la censura. La imagen de la guerra y su descripción escrita tienen características y riesgos específicos que una "buena" censura, o sea una censura eficiente, sabe reconocer. Los censores son por esencia, que no por diploma, semiólogos pero la imagen es resistente a la semiología, tanto a sus técnicas de descomposición como a las de descodificación (esta dificultad llega a generar dudas sobre la pertinencia general de la disciplina). Por otro lado, como afirma el psicólogo especialista de la imagen Alain Tisseron ${ }^{21}$, generalmente los investigadores han sobrestimado la significación y descuidado otros aspectos de la comunicación, como la transmisión de sensaciones, de emociones y de propensión a la acción, que es donde precisamente la imagen tiene mayor capacidad de transmisión. Por ello, para el censor la imagen es, aún si cabe, más perversa, más indomable, más insoportable que la palabra.

21. Tisseron, Serge, Psychanalyse de l'image, Paris, Dunod, 2005.

El autor quiere expresar su agradecimiento a Carmela Guerrero Acosta por su inestimable ayuda en la formulación en lengua castellana de este artículo. 